Supplementary Online Material

for

\title{
Modeling the hydrology and physiology of Sphagnum moss in a northern temperate bog
}

Xiaoying Shi ${ }^{1 *}$, Daniel M. Ricciuto ${ }^{1}$, Peter E. Thornton ${ }^{1}$, Xiaofeng $\mathrm{Xu}^{2}$, Fengming Yuan ${ }^{1}$, Richard J. Norby ${ }^{1}$, Anthony P. Walker ${ }^{1}$, Jeffrey Warren ${ }^{1}$, Jiafu Mao ${ }^{1}$, Paul J. Hanson ${ }^{1}$, Lin Meng ${ }^{3}$, David Weston ${ }^{1}$, Natalie A. Griffiths ${ }^{1}$

${ }^{1}$ Climate Change Science Institute and Environmental Sciences Division, Oak Ridge National Laboratory, Oak Ridge, TN 37831, USA

${ }^{2}$ Biology Department San Diego State University, San Diego, CA, 92182-4614, USA

${ }^{3}$ Department of Geological and Atmospheric Sciences, lowa State University, Ames, IA, 50011

Corresponding author's email: shix@ornl.gov

This file contains Figure S1, S2 and S3. 


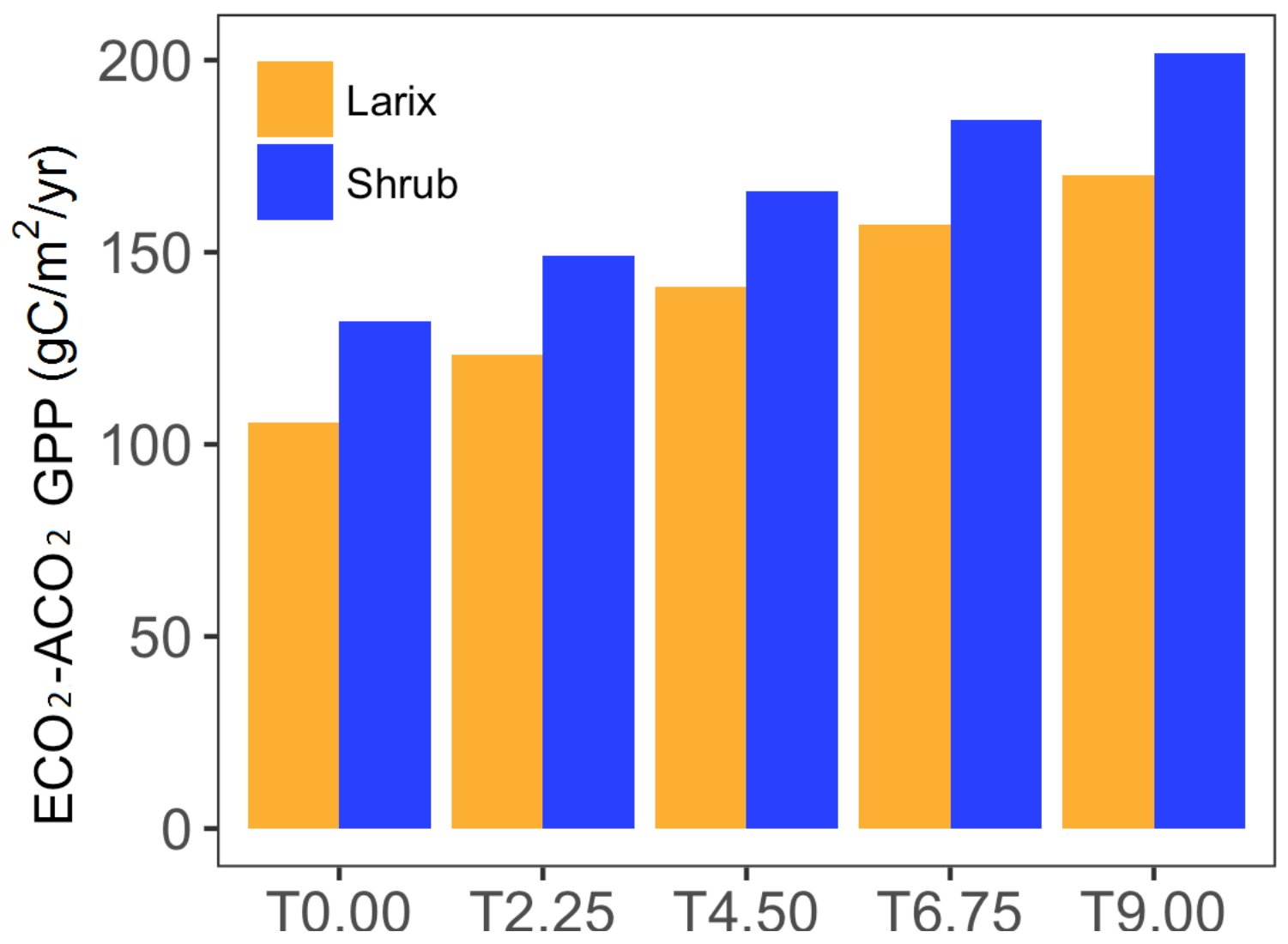

Figure $\mathrm{S} 1$. The differences between the elevated and ambient $\mathrm{CO}_{2}$ with warming conditions $\left(\mathrm{ECO}_{2}-\mathrm{ACO}_{2}\right)$ for modeled potential GPP for Larix and shrub species. 

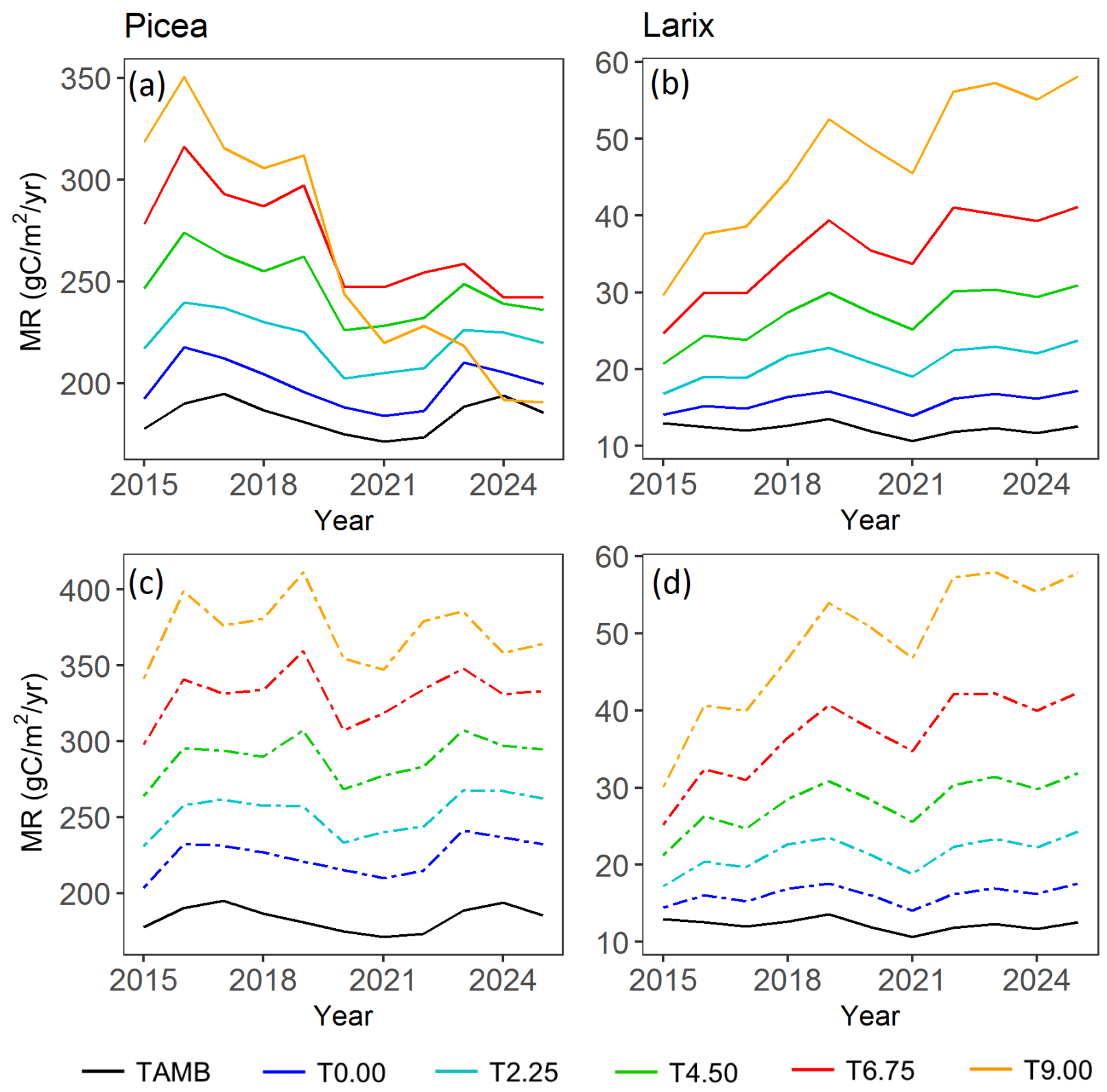

Figure S2 predicted MR response to warming with ambient atmospheric CO2 (a-b, solid lines) and warming with elevated atmospheric $\mathrm{CO}_{2}$ concentration (c-d, dash lines), the black solid line TAMB is the ambient temperature and $\mathrm{CO}_{2}$ case, T0.00 to T9.00 means increasing temperature from $0^{\circ} \mathrm{C}$ to $9^{\circ} \mathrm{C}$. 


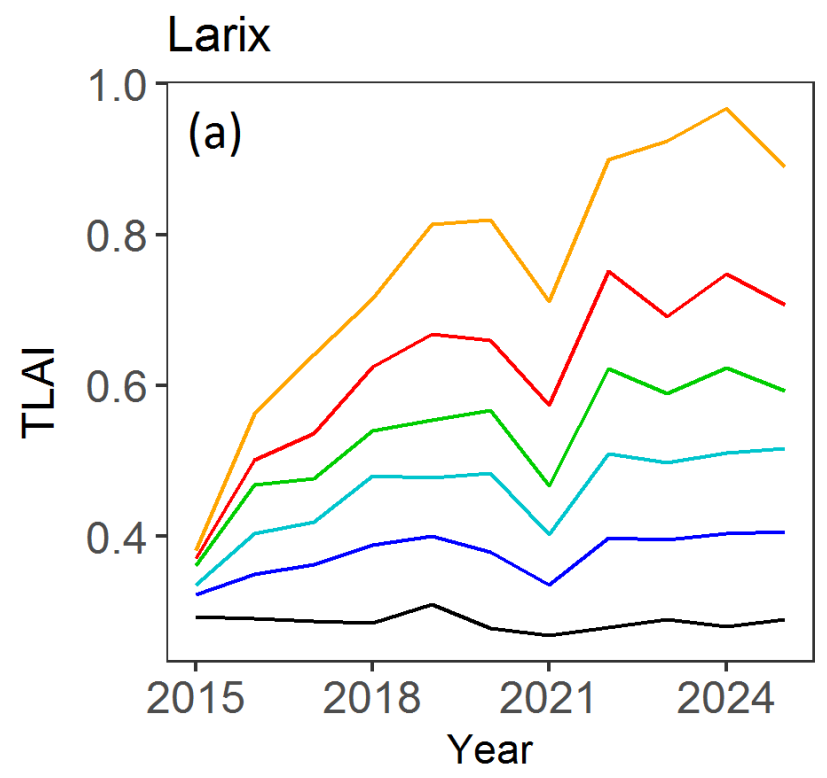

Shrub
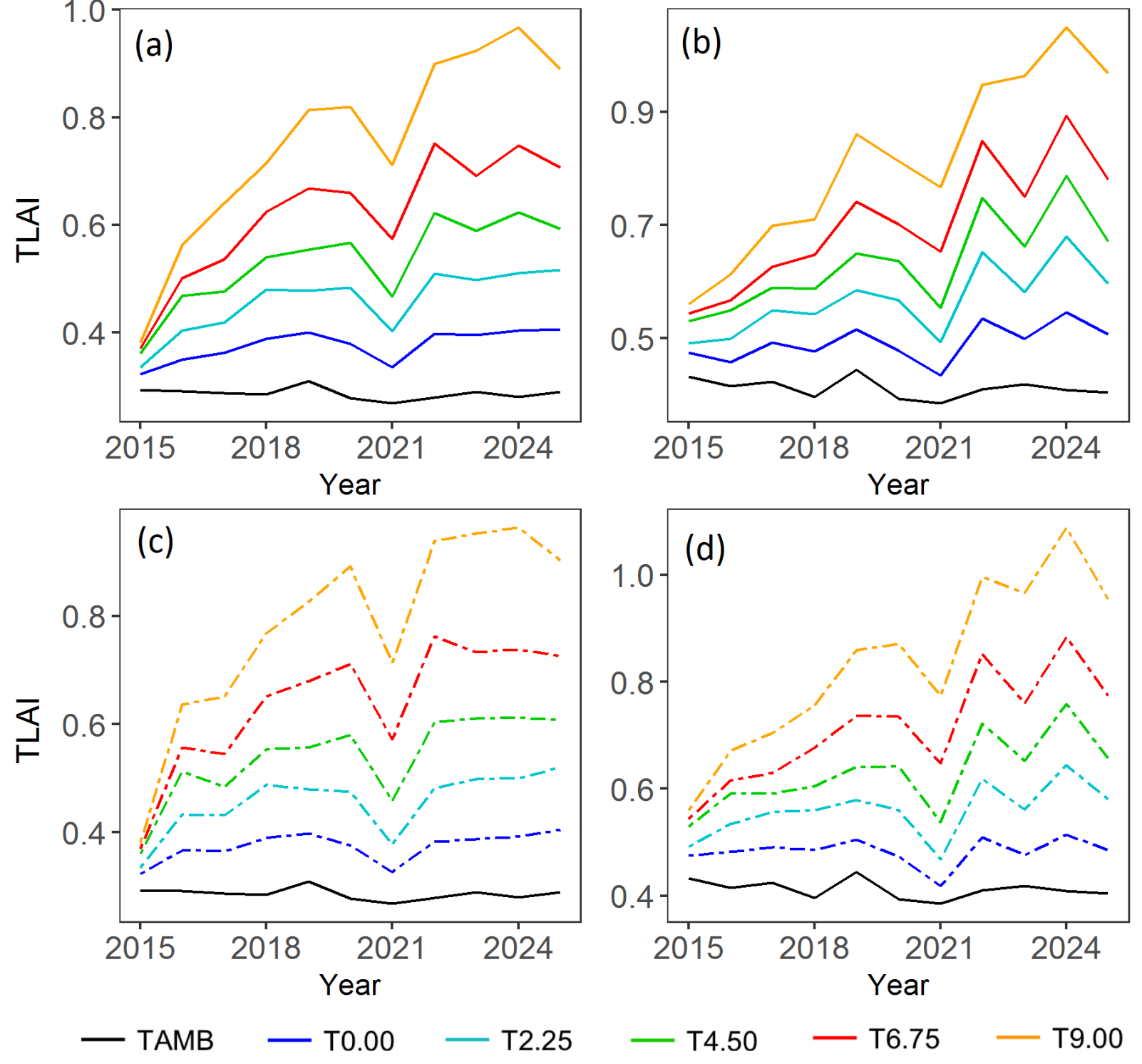

Figure S3 predicted leaf area index response to warming with ambient atmospheric $\mathrm{CO}_{2}(a-b$, solid lines) and warming with elevated atmospheric $\mathrm{CO}_{2}$ concentration (c-d, dash lines), the black solid line TAMB is the ambient temperature and $\mathrm{CO}_{2}$ case, T0.00 to T9.00 means increasing temperature from $0^{\circ} \mathrm{C}$ to $9^{\circ} \mathrm{C}$. 